Research Article

\title{
Effect of Exogenous Melatonin on the Quality of Soybean and Natto Products under Drought Stress
}

\author{
Liang Cao $\mathbb{D}^{1},{ }^{1}$ Fang Kou $\mathbb{C D}^{2}{ }^{2}$ Mingcong Zhang, ${ }^{1}$ Xijun Jin, ${ }^{1}$ Chunyuan Ren, ${ }^{1}$ Gaobo Yu, \\ Yuxian Zhang $\mathbb{D}^{1}{ }^{1}$ and Mengxue Wang ${ }^{1}$ \\ ${ }^{1}$ College of Agricultural, Heilongjiang Bayi Agricultural University, Xinfeng Lu 5, Daqing 163319, China \\ ${ }^{2}$ College of Food, Gangneung-Wonju National University, Gangneung, Gangwon, Republic of Korea \\ Correspondence should be addressed to Yuxian Zhang; zyx_lxy@126.com
}

Received 10 September 2020; Revised 2 April 2021; Accepted 11 April 2021; Published 20 April 2021

Academic Editor: Irene Dini

Copyright (c) 2021 Liang Cao et al. This is an open access article distributed under the Creative Commons Attribution License, which permits unrestricted use, distribution, and reproduction in any medium, provided the original work is properly cited.

\begin{abstract}
Melatonin can directly or indirectly eliminate reactive oxygen species, regulate hormone levels, and improve drought-stressed soybean crop resistance, yield, and quality. The nutrient contents of soybeans grown under normal conditions (WW), drought stress (D), and drought stress with exogenous melatonin $(D+M)(p<0.05)$ were compared. The differences in the quality of natto from the three groups of soybeans were also analyzed. The results showed that compared with soybeans under normal conditions, those grown under drought stress had reduced yield and carbohydrate, protein, essential amino acid, soybean isoflavone, and other nutrient contents. Besides, natto presented low nattokinase levels $(674 \mathrm{U} / \mathrm{mL})$, natto drawing ability was weak, the surface was dull, the taste was poor, and the sensory score was 12 points. Exogenous melatonin increased the carbohydrate content (starch, sucrose, glucose, and fructose) and improved the yield and quality of soybeans under drought. The natto produced by soybeans under drought stress with exogenous melatonin had high nattokinase content $(756 \mathrm{U} / \mathrm{mL})$ and long wire drawing. The surface of the product was rich in mucus and had a natto aroma. Its comprehensive sensory score was 20 points. Natto from soybeans under drought stress that were treated with exogenous melatonin showed significantly higher yield, nutrient content, and quality, than those under drought stress without treatment. This study provides theoretical data that can facilitate the development of new methods to improve the quality of soybeans grown under drought conditions.
\end{abstract}

\section{Introduction}

Drought reduces the water content of soybean leaves and the integrity of cell membrane, which limits the orderly progress of physiological [1] and biochemical reactions, such as carbon and nitrogen assimilation, transfer, and distribution during soybean growth, and thereby leads to slow crop growth and development [2, 3]. Drought also reduces soybean yield $[4,5]$ and nutrient accumulation, affecting soybean quality [6-10] and food security [11]. Studies have shown that melatonin (N-acetyl-5-methoxytryptamine) can effectively increase the activity of antioxidant [12] and glutathione-related enzymes and reduce the damage caused by ROS (reactive oxygen species) to cell membrane $[13,14]$. Melatonin also regulates the levels of growth hormones and improves the activities of carbon and nitrogen metabolism- related enzymes and photosynthetic rate $[15,16]$, thus promoting carbon and nitrogen metabolism and improving yield and quality of soybean. Concomitantly, the expression and regulation of genes related to "amino acid metabolism" and "starch-sucrose metabolism" pathways are upregulated, and the contents of L-asparagine and 6-phosphate glucose metabolites are increased, thus playing a role in drought resistance $[17,18]$.

Natto is a fermented soybean product, and its minerals and isoflavones are not easily lost after processing. Nattokinase, one of the most important active substances in natto, dissolves thrombus, reduces blood viscosity, improves blood circulation, and softens and increases blood-vessel elasticity. It can also reduce the risk of death due to cardiovascular diseases in both men and women. Its surface is covered with white viscous material, which can form mucus after stirring. 
The silky sticky mucus is an important criterion in determining the quality of natto.

Because of a major imbalance between the supply and demand of soybean in China, the soybean yield in Heilongjiang has been declining annually, and it has been difficult for the soybean quality to meet the production standards and requirements. Compared with other methods for conferring drought resistance, the application of melatonin is a simple, effective method that requires low technical skill to improve drought resistance and promote crop growth and yield. Although there are studies on melatonin application and the improvement of antioxidant and drought resistance properties of crops, there is a lack of data on the influence of melatonin treatment on the nutritional composition and quality of soybean and its products. In this study, we explored whether the application of melatonin would improve drought resistance and quality of soybean and its products (such as natto) under drought stress, while aiming at utilizing the findings to improve the quality of soybean products in the future.

\section{Materials and Methods}

2.1. Test Materials. The drought-sensitive soybean variety Suinong 26 was provided by the National Engineering Technology Research Center for Coarse Cereals, China; Bacillus subtilis var. natto strains were purified from commercially available natto starter cultures (MG) bought from Miyagino natto Production Research Institute, Japan; beef extract peptone (NA) agar medium, daidzin, glycerin, genistin, genistein, urokinase standards, fibrin tablets, and daidzein were purchased from Beijing Obosing Biotechnology Co., Ltd., China.

2.2. Instruments and Equipment. The $\mathrm{PH} 104 \mathrm{~A}$ constanttemperature incubator was purchased from Shanghai Yiheng Technology Co., Ltd., Shanghai, China; the 4802UV/ VIS ultraviolet-visible spectrophotometer was purchased from Unocal Instrument Co., Ltd.; the G154DW autoclave steam sterilizer was purchased from Zhiwei Instrument Co., Ltd.; and the A300 advanced amino acid automatic analyzer was purchased from MembraPure Instrument Co., Ltd., Germany.

\subsection{Experimental Methods}

2.3.1. Sample Processing. Sui Nong 26 was used as the test variety. The pot cultivation barrel diameter was $30.0 \mathrm{~cm}$, and the height was $33.0 \mathrm{~cm}$. Six seeds were sown in each pot, and three of the seedlings with moderate growth vigor were selected for the experiment. The beginning period of grain filling was recorded as the first day of the experiment, and the field capacity was controlled at $80 \%$. The vermiculite, perlite, and chernozem were mixed in the ratio of 1:3:12 (v:v: $\mathrm{v}$ ), and the physicochemical properties (alkali hydrolyzable nitrogen $72.1 \mathrm{mg} \mathrm{kg}^{-1}$, available phosphorus $14.1 \mathrm{mg} \mathrm{kg}^{-1}$, available potassium $173.0 \mathrm{mg} \mathrm{kg}^{-1}, \mathrm{pH} 7.1$, and organic matter $3.9 \mathrm{mg} \mathrm{kg}^{-1}$ ) were used as substrates. The amount of fertilizer was $0.3 \mathrm{~g}$ DAP, $0.075 \mathrm{~g}$ urea, and $0.075 \mathrm{~g}$ potassium sulfate per $\mathrm{kg}$ of soil. Each treatment pot weighed $0.5 \mathrm{~kg}$ and contained $16.5 \mathrm{~kg}$ soil. Each treatment consisted of 100 pots, and it was performed in triplicate. The specific treatment settings are as follows.

In normal water supply treatment (WW), the soil moisture content was maintained at $80 \%$ water holding capacity (WHC). In drought-stress treatment (D), the soil WHC reached $50 \%$ on the $10^{\text {th }}$ day to reach the drought standard; from $11^{\text {th }}$ to $27^{\text {th }}$ day, the drought standard of $50 \%$ WHC was maintained by replenishing water. To ascertain normal plant growth, $80 \%$ of the WHC of the soil was adopted at $28 \mathrm{~d}$ until harvest at maturity. Drought-stress plants were sprayed with melatonin $(D+M)$, when reaching the drought standard on the $10^{\text {th }}$ day, $20 \mathrm{~mL}$ of $100 \mu \mathrm{mol} / \mathrm{L}$ melatonin was sprayed on soybean leaves at $21: 00$ on $11^{\text {th }}$, $12^{\text {th }}$, and $13^{\text {th }}$ day, at the same time keeping the WHC reached $50 \%$. After that, WHC is kept at $80 \%$ at $28^{\text {th }}$ day until harvest at maturity.

2.3.2. Nutrient Composition Testing. The starch content was determined by the GB/T 5009.9 method [19]; the sucrose, fructose, and glucose contents were determined according to the method described by Zhang et al. [20]; soybean protein and amino acid contents were determined according to the GB/T 14489.2-2008 method [21]; and isoflavone content was determined according to the method described by Ye et al. [22].

2.3.3. Natto Fermentation Process. Soybean grains were screened, washed, and soaked in water for $20 \mathrm{~h}$. The grains were placed in an oven at $121^{\circ} \mathrm{C}$ for $35 \mathrm{~min}$ and then cooled. $4 \%$ of natto starter cultures (MG) was inoculated in soybean after cooking. Grains were fermented at $37^{\circ} \mathrm{C}$ and $90 \% \mathrm{RH}$ for $24 \mathrm{~h}$. Natto was obtained after maintaining the grains at $4^{\circ} \mathrm{C}$ for $24 \mathrm{~h}$.

2.3.4. Determination of Nattokinase Activity. Nattokinase activity was measured according to the method described by Xiong et al. [23]. Fibrin plate method was used to determine the nattokinase activity in the crude natto enzyme solution. Two grams of the prepared natto were added to $6 \mathrm{~mL}$ of sterile physiological saline, and the solution was left at $4^{\circ} \mathrm{C}$ for $24 \mathrm{~h}$ or $30^{\circ} \mathrm{C}$ for $30 \mathrm{~min}$ with shaking. It was centrifuged at $4^{\circ} \mathrm{C}, 10,000 \times \mathrm{g}$ for $10 \mathrm{~min}$, and $2 \mu \mathrm{L}$ of the supernatant crude enzyme was used. The liquid was distributed in the wells of the fibrin plate by making three parallel streaks for each sample; the plates were incubated at $37^{\circ} \mathrm{C}$ for $8 \mathrm{~h}$. The diameter of the dissolution circle was measured with a Vernier caliper, and the average area was calculated. The nattokinase activity of the crude natto enzyme solution produced by the strain was analyzed according to the urokinase standard curve.

2.3.5. Sensory Evaluation of Natto. A 20-point system of four indicators was used for scoring (Table 1). A sensory evaluation team was composed of 20 people, and a blind 
TABLE 1: Criteria for sensory evaluation.

\begin{tabular}{|c|c|c|c|c|}
\hline Score & Appearance & Brushed & Smell & Taste \\
\hline $0-3$ & Beans are distinct, and the surface is dark brown & Almost no mucus, $0-10 \mathrm{~cm}$ & $\begin{array}{c}\text { Strong } \\
\text { ammonia smell } \\
\end{array}$ & $\begin{array}{l}\text { Not soft, no mucus, dry, } \\
\text { astringent, bitter }\end{array}$ \\
\hline $4-7$ & The beans are loose and brown on the surface & There is less mucus, $10-20 \mathrm{~cm}$ & $\begin{array}{c}\text { Heavy } \\
\text { ammonia smell }\end{array}$ & $\begin{array}{l}\text { Soft, waxy, dry, } \\
\text { astringent, not bitter }\end{array}$ \\
\hline $8-11$ & $\begin{array}{l}\text { The bean grains are not easy to separate, and the } \\
\text { surface is dull }\end{array}$ & $\begin{array}{l}\text { The mucus is normal, and the } \\
\text { viscosity is strong, } 20-30 \mathrm{~cm}\end{array}$ & $\begin{array}{c}\text { Ammonia } \\
\text { smell }\end{array}$ & $\begin{array}{l}\text { Soft, waxy, moist, not } \\
\text { astringent, not bitter }\end{array}$ \\
\hline $12-15$ & $\begin{array}{c}\text { Grains are compact, the color is dull, there is white } \\
\text { powder attached to the surface, and the surface is } \\
\text { shiny }\end{array}$ & $\begin{array}{l}\text { There is more mucus and } \\
\text { strong viscosity, } 30-40 \mathrm{~cm}\end{array}$ & $\begin{array}{l}\text { Minor } \\
\text { ammonia smell }\end{array}$ & $\begin{array}{l}\text { Soft, waxy, moist, not } \\
\text { astringent, not bitter }\end{array}$ \\
\hline $16-20$ & $\begin{array}{l}\text { Bean grains have strong adhesiveness, bright color, } \\
\text { white powdery attachments, and shiny surface }\end{array}$ & $\begin{array}{l}\text { A lot of mucus and strong } \\
\text { viscosity, } 40-50 \mathrm{~cm}\end{array}$ & Natto aroma & $\begin{array}{l}\text { Soft, waxy, slippery, not } \\
\text { astringent, not bitter }\end{array}$ \\
\hline
\end{tabular}

evaluation model was adopted. The highest and lowest scores were removed. The experiment designer did not participate in the scoring, and the average of the 18 scores was taken. The drawing score of the natto is to stir the natto evenly for 2 min, observe the amount of mucus, and then pick up with chopsticks to measure the drawing length [24].

2.3.6. Data Processing and Analysis. Microsoft Excel 2013 was used for data entry and sorting. All experiments were conducted in triplicates $(n=3)$, and results were displayed as mean \pm SD. SPSS 19.0 software (Chicago, IBM SPSS, USA) was used for variance analysis and Origin 9.1 software (Northampton, MA, USA) was used for illustrations; $p$ values $<0.05$ were considered statistically significant.

\section{Results}

3.1. The Effect of Exogenous Melatonin on Soybean Yield under Drought Stress. As shown in Table 2, drought stress reduced the number of pods, grain weight and grain per plant, 100 grain weight, and ultimately yield. There were significant differences in the number of pods and seeds per plant, 100 grain weight, and grain per plant between the WW and D treatments. These were reduced in treatment $\mathrm{D}$ by $7.04 \%$, $8.07 \%, 28.75 \%$, and $27.70 \%$, respectively. Compared with D treatment, the above indicators of $\mathrm{D}+\mathrm{M}$ treatment increased by $2.02 \%, 5.77 \%, 12.91 \%$, and $10.86 \%$, respectively. The differences between $\mathrm{D}$ and $\mathrm{D}+\mathrm{M}$ treatments in grain weight, 100-grain weight, and yield reached significant levels. Based on the production data of 2018 and 2019, spraying exogenous melatonin under drought stress can effectively prevent the decrease in the number of pods per plant, the number of grains per plant, 100 grain weight, and grain weight per plant, and ultimately increase the soybean yield under drought stress.

3.2. The Effect of Exogenous Melatonin on Soybean Carbohydrate Content under Drought Stress. As shown in Figure 1, compared with WW treatment, the soybean starch, sucrose, and glucose content of D treatment decreased by $30.5 \%$, $9.83 \%$, and $9.14 \%$, while the fructose content increased by $70.12 \%$. Compared with D treatment, the soybean starch, sucrose, fructose, and glucose content of D+M treatment increased by $24.01 \%, 19.67 \%, 34.92 \%$, and $19.70 \%$, respectively. These results indicate that the addition of exogenous melatonin can significantly increase the content of sugars in soybean under drought stress.

\subsection{The Effect of Exogenous Melatonin on Soybean Protein} Content under Drought Stress. Figure 2 shows that the protein content of D soybean was significantly lower than that of the WW and D $+\mathrm{M}$ groups. This result was because drought stress decreased the activity of key enzymes in nitrogen metabolism, increased inorganic nitrogen content, decreased amino-acid content, and blocked nitrogen accumulation and transportation. Under drought stress, exogenous melatonin can significantly increase the activities of key enzymes in nitrogen metabolism (NR, GS, GOGAT, and $\mathrm{GDH}$ ), increase amino acid content, promote nitrogen accumulation in the whole plant, and facilitate nitrogen assimilation and transportation [25].

3.4. The Effect of Exogenous Melatonin on Soybean Essential Amino Acid Content under Drought Stress. Amino acids play a positive role in crop resistance. As shown in Figure 3, compared with the WW group, D group had decreased lysine (Lys), tryptophan (Tyr), methionine (Met), and threonine (Thr), leucine (Leu), isoleucine (Ile), valine (Val), and phenylalanine (Phe) content. Compared with the D group, the Thr, Tyr, Met, Thr, Leu, Ile, Val, and Phe contents of the $\mathrm{D}+\mathrm{M}$ group had increased, suggesting that spraying exogenous melatonin can increase the essential amino acid content of soybean.

\subsection{Effect of Exogenous Melatonin on Soybean Isoflavone} Content under Drought Stress. Table 3 shows that drought stress caused a significant decrease in the isoflavone content of mature soybean grains. Compared with WW treatment, daidzin, glycitin, genistin, genistein, and total isoflavones contents were reduced by $9.28 \%, 15.15 \%, 14.31 \%, 20.71 \%$, and $12.62 \%$ in $\mathrm{D}$ treatment, respectively. Spraying exogenous melatonin increased the contents of the above indicators in $\mathrm{D}+\mathrm{M}$ treatment, and the above indicators increased by $3.14 \%, 8.24 \%, 6.23 \%, 25.00 \%, 5.66 \%$, respectively, except for genistein. Besides, there were significant differences in other indicators according to varying 
TABLE 2: Effects of melatonin treatment on yield components of soybean under drought stress.

\begin{tabular}{cccccc}
\hline Year & Treatment & Pod number per plant & $\begin{array}{c}\text { Grain number } \\
\text { per plant }\end{array}$ & 100 grain weight/g & g/plant \\
\hline & & & $47.10 \pm 0.99 \mathrm{a}$ & $23.76 \pm 2.78 \mathrm{a}$ & $10.83 \pm 0.70 \mathrm{a}$ \\
2018 & WW & $21.30 \pm 1.25 \mathrm{a}$ & $43.30 \pm 1.16 \mathrm{c}$ & $17.35 \pm 0.97 \mathrm{c}$ & $7.83 \pm 0.60 \mathrm{c}$ \\
& D & $19.80 \pm 0.79 \mathrm{~b}$ & $45.80 \pm 1.03 \mathrm{~b}$ & $19.59 \pm 1.30 \mathrm{~b}$ & $8.68 \pm 0.72 \mathrm{~b}$ \\
\hline & D + M & $20.20 \pm 1.23 \mathrm{ab}$ & $46.53 \pm 0.48 \mathrm{ab}$ & $23.10 \pm 0.36 \mathrm{a}$ & $10.85 \pm 1.08 \mathrm{a}$ \\
2019 & WW & $21.50 \pm 3.27 \mathrm{a}$ & $43.73 \pm 0.33 \mathrm{c}$ & $17.83 \pm 0.93 \mathrm{c}$ & $7.80 \pm 0.75 \mathrm{c}$ \\
& $\mathrm{D}$ & $18.20 \pm 1.99 \mathrm{~b}$ & $45.47 \pm 0.66 \mathrm{~b}$ & $19.28 \pm 1.25 \mathrm{~b}$ & $8.77 \pm 0.92 \mathrm{~b}$ \\
\hline
\end{tabular}

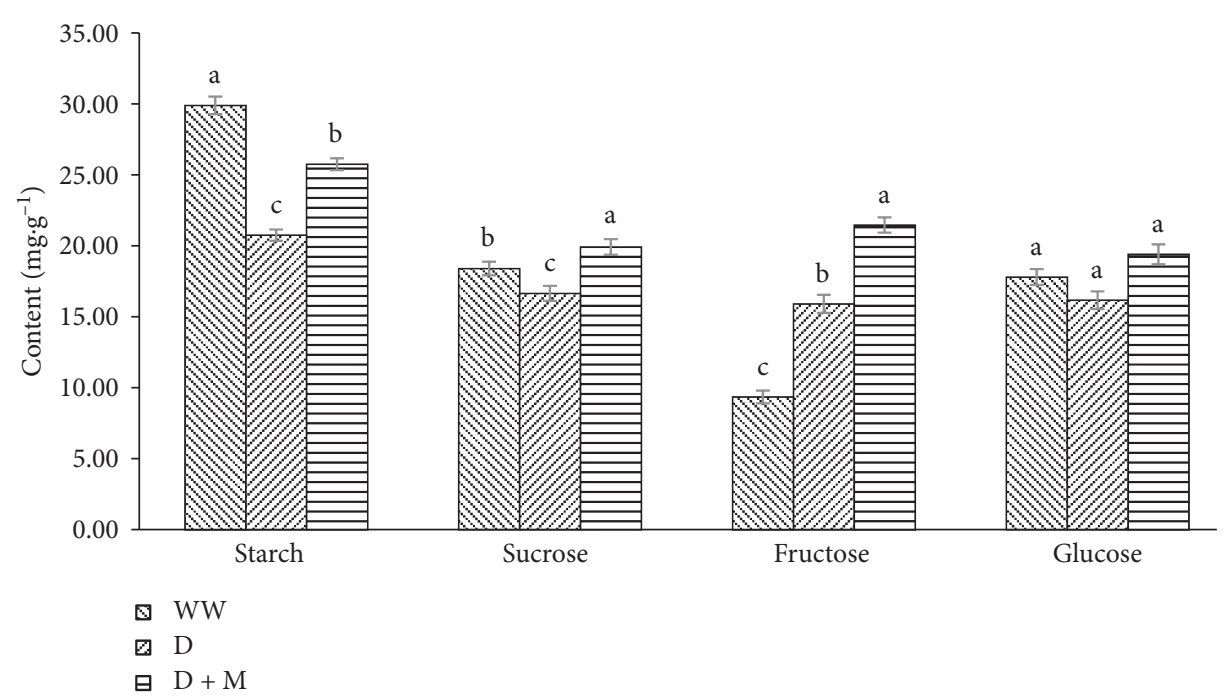

FIGURE 1: Effect of melatonin on carbohydrate contents in soybean under drought stress. Data are represented as average \pm SD $(n=3)$. Different letters indicate significant differences $(p<0.05)$.

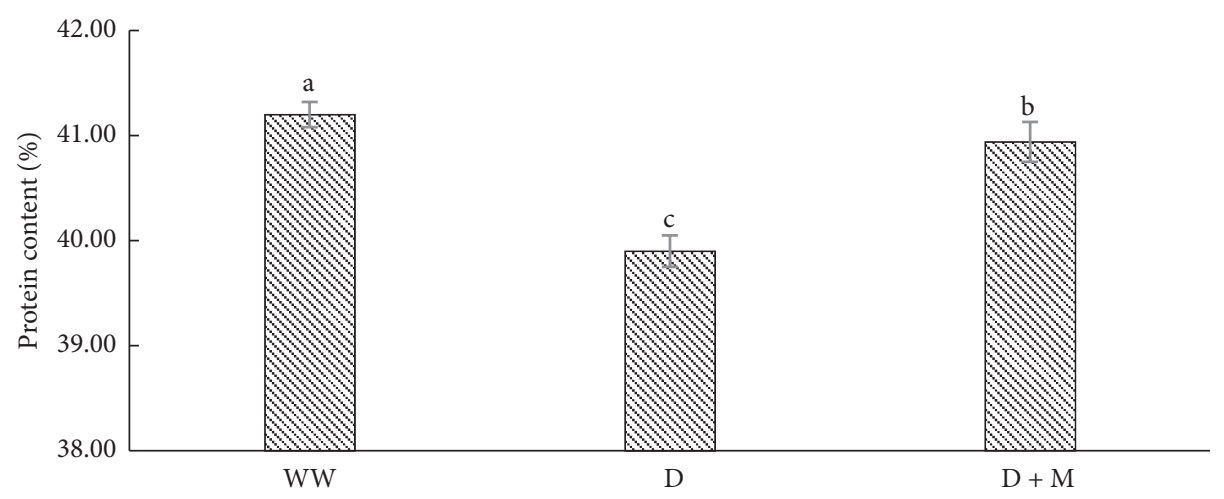

FIGURE 2: Effect of melatonin on protein contents in soybean under drought stress. Data are represented as average \pm SD $(n=3)$. Different letters indicate significant differences $(p<0.05)$.

treatments, suggesting that melatonin can promote the increase in isoflavone content of mature soybean grains.

3.6. Nattokinase Activity in Natto. The concentrations of urokinase and natto crude enzyme solution were different; the size of the dissolution circle after the reaction on the fibrin plate was also different. Nattokinase activity was calculated according to the standard curve of urokinase $y=8.1034 \times-909.13\left(R^{2}=0.9991\right)$. The results showed that nattokinase activity of the natto products obtained from the three treatments were $731 \mathrm{U} / \mathrm{mL}, 674 \mathrm{U} / \mathrm{mL}$, and $756 \mathrm{U} / \mathrm{mL}$, respectively. This result suggests that $\mathrm{D}+\mathrm{M}$ treatment was more conducive for the growth of natto bacteria, thereby producing more biologically active substances such as nattokinase, which improves the nutrition contents and sales of the natto products.

3.7. Sensory Evaluation of Natto. The appearance, drawing length, smell, and taste of natto are also important factors affecting its commodity value. The higher the yield of 


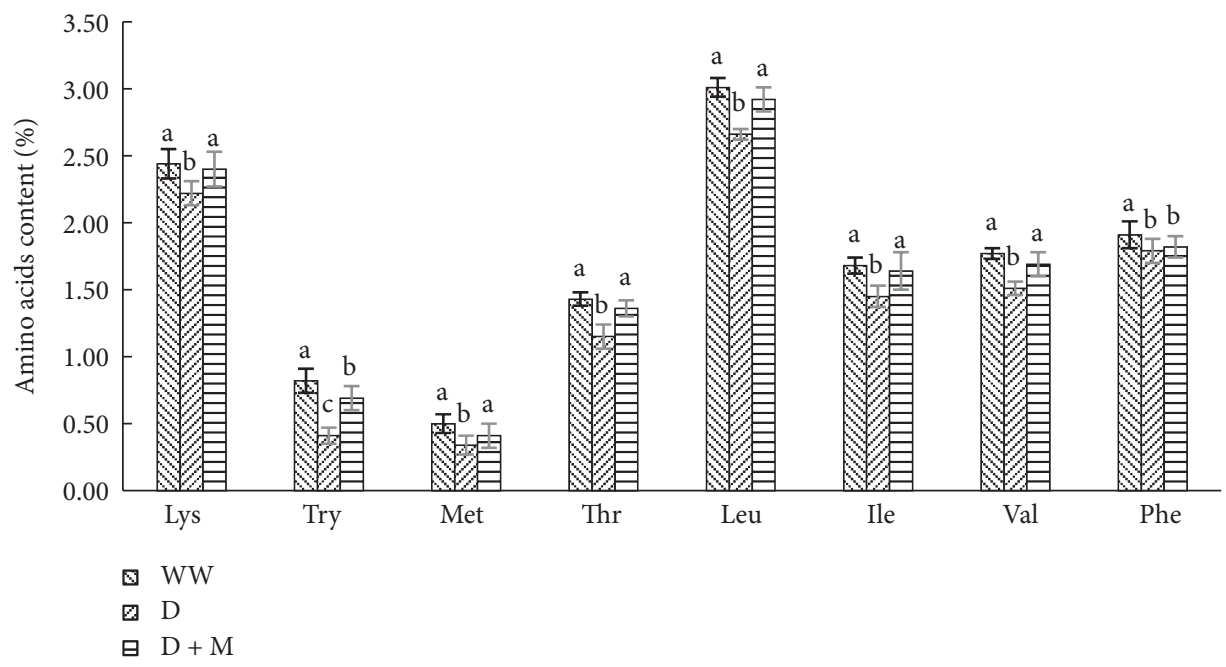

FIGURE 3: Effect of exogenous melatonin on amino acid content in soybean under drought stress. Data are represented as average \pm SD $(n=3)$. Different letters indicate significant differences $(p<0.05)$.

TABLE 3: Effect of exogenous melatonin on the isoflavone content in soybean under drought stress.

\begin{tabular}{lcccrr}
\hline Treatment & Daidzin $\left(\mu \mathrm{g} \cdot \mathrm{g}^{-1}\right)$ & Glycitin $\left(\mu \mathrm{g} \cdot \mathrm{g}^{-1}\right)$ & Genistin $\left(\mu \mathrm{g} \cdot \mathrm{g}^{-1}\right)$ & Genistein $\left(\mu \mathrm{g} \cdot \mathrm{g}^{-1}\right)$ & $\begin{array}{c}\text { Total isoflavones } \\
\left(\mu \mathrm{g} \cdot \mathrm{g}^{-1}\right)\end{array}$ \\
\hline WW & $168.29 \pm 0.62 \mathrm{a}$ & $49.56 \pm 0.26 \mathrm{a}$ & $226.17 \pm 8.60 \mathrm{a}$ & $5.60 \pm 0.12 \mathrm{a}$ & $449.62 \pm 8.23 \mathrm{a}$ \\
$\mathrm{D}$ & $152.67 \pm 0.88 \mathrm{c}$ & $42.05 \pm 0.37 \mathrm{c}$ & $193.72 \pm 6.99 \mathrm{c}$ & $4.44 \pm 0.10 \mathrm{~b}$ & $392.89 \pm 6.59 \mathrm{c}$ \\
$\mathrm{D}+\mathrm{M}$ & $157.46 \pm 0.11 \mathrm{~b}$ & $45.55 \pm 0.22 \mathrm{~b}$ & $206.58 \pm 3.6 \mathrm{~b}$ & $5.55 \pm 0.06 \mathrm{a}$ & $415.14 \pm 3.87 \mathrm{~b}$ \\
\hline
\end{tabular}

$\gamma$-polyglutamic acid ( $\gamma$-PGA), the more will be the mucus and the better will be the drawing effect and taste [26]. As shown in Table 4, the sensory evaluation results revealed that the WW natto group had higher protein content, moist glossy surface, obvious and long drawing, high viscosity, ammonia smell, and a comprehensive sensory score of 15 points. The D natto group had the lowest protein content, poor surface gloss, nonwetting, short drawing, low viscosity, relatively poor taste, and a sensory score of 12 points. In the $\mathrm{D}+\mathrm{M}$ natto group, the soybean protein content was moderate, with bright color, longer drawing, moderate viscosity, smooth taste, and it had a natto aroma without any peculiar smell, which was in line with the taste of the Chinese people. The comprehensive sensory score was 20 points.

\section{Discussion}

Relevant research shows that the main reasons for drought to reduce crop yield were the drought would destroy the different growth stage of plant water balance in the body; reduce the antioxidant enzymes [27], sucrose phosphate synthase (SPS), sucrose synthase (SS) [28, 29], glutamine synthetase (GS) [30] activity, suppression, and cell division and chloroplast membrane structure was destroyed, resulting in the decrease of leaf area coefficient and photosynthetic rate, crop carbon, and nitrogen assimilation, metastasis; and affect the growth and development of root, stem, and leaf $[31,32]$, resulting in significant decrease in biomass [2,3]. Drought in different periods had different effects on yield and quality. Cell division was inhibited, and leaf area was decreased under drought stress at the seedling stage. Dryness in the flowering pod stage causes stunted plants, reduced carbon assimilation, abscisic acid accumulation, and pod shedding $[33,34]$. Droughts in the bulge stage mainly affect the grain formation, and the accumulation of nutrients gradually decreases [35], ultimately affecting the yield and quality [13]. Li et al. [32] believed that, with the persistence of drought stress, the contents of soluble sugar and fructose in soybean leaves increased, while the content of sucrose decreased. Zhang et al. [36] believed that drought increased the content of reducing sugar and soluble total sugar in soybean leaves at the bulging stage. Studies have shown that drought stress significantly reduced the relative water content of tomato [37], blueberry [38], wheat [39], and other crops and severely damaged the integrity of cell membranes. Grain development of wheat and sesame [40] was inhibited, eventually leading to a yield reduction of $17 \%-70 \%$ in wheat $[4,5]$, and the contents of crude fat, oleic acid, and total phenols in sesame decreased significantly. Under drought stress, the grain size and protein and amylose content of fresh maize decreased, leading to a decrease in yield and quality.

Li [41] and Marinobet [42] believed that melatonin could promote nitrogen accumulation, amino acid synthesis, and soybean yield under normal water supply and drought stress. Wang et al. [14], Zou et al. [43], Zheng et al. [44], and other scholars believe that melatonin through the activity of antioxidant enzymes reduces ROS cell membrane injury caused by the effect of soybean drought. Zhang et al. [45] and Liu's 
TABLE 4: Sensory evaluation of natto samples.

\begin{tabular}{lccccc}
\hline Sensory evaluation group & Appearance & Brushed & Odor & Taste & Comprehensive score \\
\hline WW & $5 \pm 0.5$ & $4 \pm 1.0$ & $3 \pm 1.0$ & $3 \pm 1.0$ & $15 \pm 1.0$ \\
D & $3 \pm 1.0$ & $2 \pm 0.5$ & $4 \pm 0.5$ & $3 \pm 1.0$ & $12 \pm 0.5$ \\
D + M & $5 \pm 0.5$ & $5 \pm 0.5$ & $5 \pm 1.0$ & $5 \pm 0.5$ & $20 \pm 0.5$ \\
\hline
\end{tabular}

research [46] suggests that melatonin by increasing the growth of soybean plant hormones IAA, GA, and ZR contents has the effect of drought resistance and promote growth. Therefore, to alleviate the effect of drought stress on soybean growth and development, it was verified that melatonin could increase soybean yield under drought stress, and the melatonin was used to spray soybean leaf surface. The results of this study showed that the growth of soybean was inhibited under drought stress, leading to low yield, poor composition, and quality of soybean, while the addition of melatonin could significantly improve the yield of soybean under drought stress, promote the accumulation of sugar, protein, amino acid, and soybean isoflavones, and thus improve the nutritional value and product quality of soybean.

\section{Conclusion}

The results of this study showed that melatonin spraying improved drought resistance of soybean. Melatonin can effectively alleviate the low yield of soybean and increase the content of carbohydrate, protein, amino acid, and soybean isoflavones under drought stress. Compared with D treatment, soybean yield of $\mathrm{D}+\mathrm{W}$ treatment increased by $10.86 \%$, illustrating that the melatonin can effectively alleviate the low yield of soybean caused by drought. The soybean starch, sucrose, fructose, and glucose content in $\mathrm{D}+\mathrm{W}$ treatment had increased by $24.01 \%, 19.67 \%, 34.92 \%$, and $19.70 \%$, protein increased by $2.6 \%$, and daidzein, glycitin, genistin, genistein, and total soybean isoflavone increase by $3.14 \%, 8.24 \%, 6.23 \%$, $25.00 \%$, and $5.66 \%$. It indicates that melatonin spraying can effectively increase the nutritional content of soybeans, thus improving the quality of soybeans. In addition, the soybean product of natto has good taste and flavor. This study clarifies the effects of drought stress and addition of exogenous melatonin on soybean nutrient components and natto quality and provides theoretical data that support soybean quality improvement.

\section{Data Availability}

The data used to support the results of this study are available from the corresponding author upon request.

\section{Disclosure}

Liang Cao and Fang Kou are co-first authors.

\section{Conflicts of Interest}

The authors declare that there are no conflicts of interest regarding the publication of this paper.

\section{Authors' Contributions}

Liang Cao and Fang Kou contributed equally to this work. Yuxian Zhang conceptualized the study, did investigation, did funding acquisition, and wrote the original draft; Liang Cao and Fang Kou developed methodology and reviewed and edited the article; Mingcong Zhang did investigation, validated the study, and did formal analysis; Xijun Jin, Chunyuan Ren, and Gaobo Yu developed methodology and reviewed and edited the article; Mengxue Wang conceptualized the study, developed methodology, supervised the study, and reviewed and edited the article. All authors have read and agreed to the published version of the manuscript.

\section{Acknowledgments}

The authors would like to thank Editage (http://www. editage.cn) for English language editing. This study was supported by the National Key Research and Development Program of China (2018YFD1000905), Research Initiation Plan for Talent Introduction (XYB202011), the Heilongjiang Application Technology Research and Development Projects (GA19B101-02), and the Heilongjiang Provincial Land Reclamation Bureau Key Research Project (HKKY19020601).

\section{References}

[1] Y. Y. An and Z. S. Liang, "Phased strategies for plants to cope with drought stress," Journal of Applied Ecology, vol. 23, no. 10, pp. 2907-2915, 2012.

[2] A. Songy, O. Fernandez, C. Clément, P. Larignon, and F. Fontaine, "Grapevine trunk diseases under thermal and water stresses," Planta, vol. 249, no. 6, pp. 1655-1679, 2019.

[3] M. Ghorchiani, H. Etesami, and H. A. Alikhani, "Improvement of growth and yield of maize under water stress by coinoculating an arbuscular mycorrhizal fungus and a plant growth promoting rhizobacterium together with phosphate fertilizers," Agriculture, Ecosystems and Environment, vol. 258, pp. 59-70, 2018.

[4] A. Nouri-Ganbalani, G. Nouri-Ganbalani, and D. Hassanpanah, "Effects of drought stress condition on the yield and yield components of advanced wheat genotypes in Ardabil, Iran," Journal of Food Agriculture \& Environment, vol. 7, no. 3, pp. 228-234, 2009.

[5] S. S. Sarah, G. Mokhtar, M. Sirous, and A. R. Zebarjadi, "The yield of wheat genotypes associated with yield components under irrigated and drought stress after anthesis," Archives of Agronomy and Soil Science, vol. 61, no. 12, pp. 1743-1755, 2015.

[6] L.-J. Shi, Z.-R. Wen, S.-B. Zhang, J. Wang, W.-P. Lu, and D.-L. Lu, "Effects of water deficit at flowering stage on yield and quality of fresh waxy maize," Acta Agronomica Sinica, vol. 44, no. 8, pp. 1205-1211, 2018. 
[7] M. Erbs, R. Manderscheid, L. Hüther et al., "Free-air CO2 enrichment modifies maize quality only under drought stress," Agronomy for Sustainable Development, vol. 35, no. 1, pp. 203-212, 2015.

[8] E. Bakhshandeh and M. Gholamhossieni, "Modelling the effects of water stress and temperature on seed germination of radish and cantaloupe," Journal of Plant Growth Regulation, vol. 38, no. 4, pp. 1402-1411, 2019.

[9] P. Högy, C. Poll, S. Marhan et al., "Impacts of temperature increase and change in precipitation pattern on crop yield and yield quality of barley," Food Chemistry, vol. 136, no. 3-4, pp. 1470-1477, 2013.

[10] R. Ahmad, R. G. M. Hur, E. A. Waraich et al., "Effect of supplemental foliar-applied potassium on cotton (Gossypium hirsutum L.) yield and lint quality under drought stress," Pakistan Journal of Life \& Social Sciences, vol. 11, no. 2, pp. 154-164, 2013.

[11] S. Talbi, M. C. Romero-Puertas, A. Hernández, L. Terrón, A. Ferchichi, and L. M. Sandalio, "Drought tolerance in a Saharian plant Oudneya africana: role of antioxidant defences," Environmental and Experimental Botany, vol. 111, pp. 114-126, 2015.

[12] P. Wang, X. Sun, C. Li, Z. Wei, and D. Liang, F. Ma, Longterm exogenous application of melatonin delays droughtinduced leaf senescence in apple," Journal of Pineal Research, vol. 54, no. 3, pp. 292-302, 2013.

[13] J. N. Zou, X. J. Jin, Y. X. Zhang et al., "The effect of exogenous melatonin on photosynthesis and growth of soybean under drought stress," Photosynthetica, vol. 57, no. 2, pp. 512-520, 2019.

[14] P. Wang, X. Sun, N. Wang, D.-X. Tan, and F. Ma, "Melatonin enhances the occurrence of autophagy induced by oxidative stress in Arabidopsis seedlings," Journal of Pineal Research, vol. 58, no. 4, pp. 479-489, 2015.

[15] J.-F. Meng, T.-F. Xu, Z.-Z. Wang, Y.-L. Fang, Z.-M. Xi, and Z.-W. Zhang, "The ameliorative effects of exogenous melatonin on grape cuttings under water-deficient stress: antioxidant metabolites, leaf anatomy, and chloroplast morphology," Journal of Pineal Research, vol. 57, no. 2, pp. 200-212, 2014.

[16] C. Li, D.-X. Tan, D. Liang, C. Chang, D. Jia, and F. Ma, "Melatonin mediates the regulation of ABA metabolism, freeradical scavenging, and stomatal behaviour in two Malus species under drought stress," Journal of Experimental Botany, vol. 66, no. 3, pp. 669-680, 2015.

[17] L. Cao, "Regulation effects of exogenous melatonin on soybean carbon and nitrogen metabolism and yield and quality under drought stress," Heilongjiang Bayi Agricultural Reclamation University, 2020.

[18] Q. Chen, W.-b. Qi, R. J. Reiter, W. Wei, and B.-M. Wang, "Exogenously applied melatonin stimulates root growth and raises endogenous indoleacetic acid in roots of etiolated seedlings of Brassica juncea," Journal of Plant Physiology, vol. 166, no. 3, pp. 324-328, 2009.

[19] China Standard Press, GB/T. 5009.9. National Food Safety Standard, Determination of Starch in Food, China Standard Press, Beijing, China, 2016.

[20] Z. L. Zhang, Guidance of Plant Physiology Experiments, pp. 128-129, Higher Education Press, Beijing, China, 2001.

[21] China Standard Press, GB/T 14489.2. Grain and Oil Inspection, Determination of Crude Protein in Vegetable Oils, China Standard Press, Beijing, China, 2008.

[22] T. Ye, Z. N. Chen, and Q. W. Ye, "The effect of different sterilization methods on instant dried soybean isoflavones and quality characteristics," Food Science, vol. 1, no. 11, pp. 12-18, 2019.

[23] Y. X. Xiong et al., "Research on the method of nattokinase activity detection," Pharmaceutical Biotechnology, vol. 13, no. 2, pp. 140-143, 2006.

[24] Y. Liu, L. Shen, K. Wang et al., "Isolation of Bacillus subtilis natto from Chinese traditional fermented soybean foods and their use in the fermentation of natto," Food Science, vol. 41, no. 2, pp. 208-214, 2020.

[25] J. X. Song, "The quality comparison of natto prepared from common beans," Soybean Science, vol. 36, no. 2, pp. 309-314, 2017.

[26] X. Y. Gao, L. J. Liu, B. Liu et al., "PEG Effects of simulated drought on antioxidant enzyme activity and antioxidant capacity of soybean," Soybean Science, vol. 35, no. 4, pp. 616-619+636, 2016.

[27] I. J. Tetlow, "Recent developments in understanding the regulation of starch metabolism in higher plants," Journal of Experimental Botany, vol. 55, no. 406, pp. 2131-2145, 2004.

[28] T. H. Li and S. H. Li, "Leaf responses of micropropagated apple plants to water stress: nonstructural carbohydrate composition and regulatory role of metabolic enzymes," Tree Physiology, vol. 25, no. 4, pp. 495-504, 2005.

[29] M. Lacuesta, C. González, C. Gonzálezcmurua et al., "Time course of the phosphinothricin effect on gas exchange and nitrate reduction in medicago sativa," Physiologia Plantarum, vol. 89, no. 4, pp. 847-853, 2006.

[30] M. A. Gururani, J. Venkatesh, L. S. Tran et al., "Regulation of photosynthesis during abiotic stress-induced photoinhibition," Molecular Plant, vol. 8, no. 9, pp. 1304-1320, 2015.

[31] M. M. Chaves, J. Flexas, and C. Pinheiro, "Photosynthesis under drought and salt stress: regulation mechanisms from whole plant to cell," Annals of Botany, vol. 103, no. 4, pp. 551-560, 2009.

[32] J. H. Li, The Effects of Exogenous ABA on Physiological Characteristics and Yield of Soybean Drought Resistance in Drum Stage under Drought Stress, Heilongjiang Bayi Agricultural Reclamation University, Daqing, China, 2017.

[33] B.-A. Farzad, T. Mahmoud, N. Majid, and S. Mohamad-Reza, "Effect of drought stress on yield and yield components of some sunflower recombinant inbred lines," International Journal of Biosciences (IJB), vol. 3, no. 3, pp. 50-56, 2013.

[34] S. Y. Lisar, I. M. Rahman, M. M. Hossain, and R. Motafakkerazad, Water Stress in Plants: Causes, Effects, and Responses, INTECH Open Access Publisher, 2012.

[35] J. N. Zou, L. Cao, M. X. Wang et al., "Effects of exogenous melatonin on photosynthesis and physiology of soybean at podding stage under drought stress," Journal of Ecology, vol. 38, no. 9, pp. 2709-2718, 2019.

[36] Q. Y. Zhang, P. Li, Y. Z. Zong et al., "Effects of drought on soybean physiology and yield," Study Journal of North China Agriculture, vol. 31, no. 5, pp. 140-145, 2016.

[37] J. R. Still and W. G. Pill, "Growth and stress tolerance of tomato seedlings (Lycopersicon esculentumMill.) in response to seed treatment with paclobutrazol," The Journal of Horticultural Science and Biotechnology, vol. 79, no. 2, pp. 197203, 2004.

[38] S. Shah, F. Shah, Y. Chen et al., "Effects of nitrogen supply on water stress and recovery mechanisms in kent bluegrass plants," Frontiers in Plant Science, vol. 8, p. 983, 2017.

[39] M. Sedaghat, Z. T. Sarvestani, Y. Emam et al., "Physiological and antioxidant responses of winter wheat cultivars to strigolactone and salicylic acid in drought," Plant Physiology and Biochemistry, vol. 119, no. 59, 2017. 
[40] A. Ozkan and M. Kulak, "Effects of water stress on growth, oil yield, fatty acid composition, and mineral content of Sesamum indicum," Journal of Animal and Plant Sciences, vol. 26, no. 6, pp. 1686-1690, 2013.

[41] H. Y. Li, X. W. Zhang, H. Y. Chen et al., "Effects of rare earth lanthanum and cerium on dry matter and grain nitrogen accumulation in soybean pods in Northeast China," Soybean Science, vol. 37, no. 3, pp. 385-392, 2018.

[42] B. Marino, "Melatonin: Synthesis from tryptophan and its role in higher plants," Amino Acids in Higher Plants, pp. 390-435, CAB International, 2015.

[43] J. N. Zou, X. J. Jin, Y. X. Zhang et al., "Effects of melatonin on photosynthesis and soybean seed growth during grain filling under drought stress," Photosynthetica, vol. 57, no. 2, pp. 512-520, 2019.

[44] C. F. Zheng, W. C. Liu, L. Wei et al., "Control of photosynthesis and ascorbic acid-glutathione cycleathione cycle of red tree Plantandelia candle under low-temperature stress," Journal of Plant Physiology, vol. 55, no. 8, pp. 1211-1221, 2019.

[45] H.-Y. Zhang, W.-X. Duan, B.-T. Xie et al., "Effects of drought stress at different growth stages on endogenous hormones and its relationship with storage root yield in sweetpotato," Acta Agronomica Sinica, vol. 44, no. 1, pp. 126-136, 2018.

[46] J. Q. Liu, L. Yang, T. Yongqiang et al., "Melatonin has the potential to alleviate cinnamic acid stress in cucumber seedlings," Frontiers in Plant Science, vol. 8, pp. 1193-1194, 2017. 